\title{
Transnacionais Brasileiras: Motivadores e Resultados do Processo de Internacionalização da Vale
}

\author{
José Dario da Conceição Menezes \\ Professor Visitante \\ Faculdades Ibmec \\ Av. Presidente Wilson, 118 sala 117 - Centro \\ 20030-020 - Rio de Janeiro-RJ \\ jdariorept@globo.com \\ Luiz Alberto Nascimento Campos Filho \\ Doutor em Engenharia de Produção - USP \\ Professor Adjunto \\ Mestrado em Administração das Faculdades Ibmec \\ Av. Presidente Wilson, 118 sala 117 - Centro \\ 20030-020 - Rio de Janeiro-RJ \\ camposfo@gmail.com
}

\section{Resumo}

Os estudos sobre estratégias de internacionalização de empresas vêm merecendo atenção crescente tanto das organizações quanto da academia, graças à importância delas no espectro de globalização e competitividade. $O$ presente trabalho analisa $o$ processo de internacionalização das três principais empresas mundiais de mineração, seus motivadores, estratégias e resultados, e verifica se o modelo utilizado apresenta relação com uma escola específica (européia, americana, japonesa ou países do BRIC), ou ainda, se foi adotado um modelo híbrido, que conjugaria as melhores práticas existentes. É realizada, em particular, a análise da internacionalização da Vale, empresa privada brasileira, com base em estudo longitudinal desde a fundação em 1942 até 2008. Para tanto foi realizada pesquisa acadêmica na literatura nacional e internacional e uma pesquisa de campo com a participação de 28 executivos que acompanham o processo de internacionalização da Vale. O resultado da pesquisa indicou a "vantagem competitiva relacionada a extração de commodities" e "foco na liderança global de sua categoria" respectivamente como os principais motivadores e estratégias empregadas na internacionalização estudada, além da verificação de um modelo híbrido de internacionalização. Foram formuladas recomendações estratégicas que visam o fortalecimento da empresa no segmento de mineração, que se encontra em franco processo de consolidação.

Palavras-chave: Processo de Internacionalização. Empresas de Mineração. Empresas Transnacionais.

\begin{abstract}
Studies on internationalization strategies of companies have been receiving increased attention from both organizations and academia, due to their importance in the spectrum of globalization and competitiveness. This paper analyzes the internationalization process of the three major global mining companies, their drivers, strategies and results, and checks whether the model used is correlated with a specific school (European, American, Japanese or the

Artigo submetido em 28 de janeiro de 2009 e aceito em 19 de maio de 2009 pelo Editor José Ricardo Maia de Siqueira, após double blind review.
\end{abstract}


BRIC countries), or, it was adopted a hybrid model, which it would combine the best practices. It is performed, specifically, the analysis of the internationalization of Vale, Brazilian private company, based on a longitudinal study since its foundation in 1942 until 2008. Thus, we conducted academic research in national and international literature and field research with the participation of 28 executives who monitor the process of internationalization of Vale. The results point out the "competitive advantage related to the extraction of commodities" and "focus on global leadership in its category" respectively as the key drivers and strategies employed in the internationalization, and the existence of a hybrid model of internationalization. It was formulated strategic recommendations aimed at strengthening the company in the mining sector, which is involved in a process of consolidation.

Key-words: Internationalization Process. Mining Companies. Transnational Companies.

\section{Introdução}

Acompanhando o processo de globalização, nos últimos anos as empresas têm avançado de forma significativa no processo de internacionalização (Booz Allen, 2007). Porém a decisão estratégica de entrada em mercados internacionais tem implicações profundas sobre o modelo de operação das empresas. Diferentemente da decisão de expandir dentro do atual território, os riscos e as incertezas envolvidas no ingresso em mercados internacionais são mais elevados quando comparados ao potencial de crescimento de receitas e lucros. O sucesso depende da capacidade de maximizar a base de ativos e conhecimentos desenvolvidos nos mercados atuais, e por outro lado; estabelecer nova base de competências, adaptada às circunstâncias e características dos mercados externos e explorá-la em escala global (Fundação Dom Cabral, 2006). Esse desafio é ainda maior dentro do segmento de mineração, no qual os investimentos são de longo prazo, que apresenta dispersão geográfica acentuada, e ainda processo preponderante de internacionalização.

O presente trabalho analisa, o processo de internacionalização das três principais empresas mundiais de mineração, seus motivadores, estratégias e resultados, além de verificar se o modelo utilizado apresenta relação com uma escola específica de internacionalização (européia, americana, japonesa ou países do BRIC) ou se foi adotado um modelo híbrido, conjugando as melhores práticas existentes. É realizada, em particular, uma análise detalhada do processo de internacionalização da Vale, empresa privada brasileira. Também são formuladas recomendações estratégicas para o fortalecimento do posicionamento competitivo da empresa dentro da indústria mundial de mineração.

Para tanto foi realizada pesquisa acadêmica na literatura nacional e internacional e uma pesquisa de campo com a participação de 28 executivos que acompanham o processo de internacionalização da Vale. Por delimitar esse escopo de investigação, cabe ressaltar que a pesquisa não contempla o desenvolvimento de análise econômica, sociológica ou política do tema.

O resultado do estudo indicou os motivadores estratégicos das empresas do segmento e em particular da Vale. Também é importante destacar que os resultados apresentados indicam que a Vale e as demais empresas analisadas, por terem feito um movimento tardio de internacionalização, não adotaram em particular as práticas de nenhuma escola, mas sim um modelo híbrido de motivadores, estratégias e resultados empregados pelas escolas americana, japonesa, países do BRIC e em menor escala as que são prescritas pela escola européia, utilizando-se das melhores e mais adequadas práticas existentes ao modelo de negócio, independentemente da influência do país-sede.

O trabalho está organizado em sete partes, que inclui esta introdução. Na segunda seção apresenta-se a metodologia da pesquisa de campo realizada para validar o estudo 
conduzido. Na quarta seção é apresentada a revisão da literatura e conceituação do modelo de internacionalização das empresas americanas, européias e japonesas além dos países do BRIC e também apresenta a análise do segmento de mineração e estudos sobre as principais empresas do segmento - BHP Billiton e Rio Tinto - e, de forma particularizada por intermédio da análise longitudinal, a empresa Vale. Na quinta seção são apresentados os resultados da pesquisa de campo conduzida, conclusões e relacionamentos com o tema estudado. Na sexta seção são explicitados os principais indicadores do processo de internacionalização da Vale e a formulação das recomendações estratégicas visando ao fortalecimento estratégico dentro do segmento de atuação. Na última seção são apresentadas as conclusões e limitações do estudo que poderão ser utilizadas no futuro por empresas nacionais que trilhem o caminho da internacionalização.

\section{Metodologia da Pesquisa}

\subsection{Pesquisa de campo}

Para a condução do processo de pesquisa necessário à conclusão do estudo foi desenvolvido um planejamento. Para isso, escolheu-se o método quantitativo com a obtenção e coleta de dados por intermédio de realização de entrevista, da definição da amostragem, da formulação do questionário estruturado, da aplicação do questionário piloto, e por último, do tratamento e da interpretação dos dados. A definição do objetivo da pesquisa deve estar vinculada perfeitamente à solução do problema de pesquisa, e a ela deve estar restrita. Além disso, devem ser considerados no estabelecimento, o tempo disponível, os recursos disponíveis, a acessibilidade aos detentores dos dados e a disponibilidade de meios de captação dessas informações (Mattar, 1999).

\subsubsection{Realização da pesquisa de campo}

Após análises do objetivo e tipo de pesquisa, optou-se pela definiçãa de dois procedimentos complementares para a obtenção de resposta. O primeiro foi a utilização da pesquisa quantitativa estruturada para a obtenção de informações por intermédio do processo de entrevista. A segunda forma foi por meio da realização da pesquisa auto-administrada, com a utilização dos recursos da Internet para vencer a resistência, a falta de tempo e até mesmo os obstáculos provocados pela distância geográfica de alguns respondentes. Cooper e Schindler (2003), afirmam que é comum encontrar procedimentos de pesquisas sendo feitas na Internet, pois a facilidade de uso e o custo são facilitadores desse tipo de opção de pesquisa. Para assegurar o sucesso do estudo, no entanto, foram tomadas precauções como o envio de mensagem prévia com a descrição do objetivo do estudo associado a uma ligação telefônica e procedimentos de acompanhamento com os receptores da respectiva pesquisa.

\subsubsection{Definição da amostra da pesquisa}

A amostra estratificada para a presente pesquisa constitui-se por um conjunto de 28 executivos de diferentes segmentos de mercado, mas que possuem como característica principal o fato de acompanharem o processo de internacionalização da Vale. Os especialistas escolhidos representam, proporcionalmente, os executivos e ex-executivos da própria Vale, bancos de investimento, empresas de mineração, o governo brasileiro - Previ e BNDES, representantes do espectro acadêmico e da imprensa especializada. Para o segmento de bancos de investimento e imprensa os nomes dos executivos foram obtidos perante a própria empresa. No caso dos integrantes da academia foram enviadas mensagens eletrônicas aos que 
publicaram trabalhos sobre internacionalização de empresas ou sobre a empresa Vale, no EnANPAD, entre 2001 e 2007. Ainda assim, muitos deles não foram localizados em razão de os endereços respectivos não corresponderem mais aos registros disponíveis. Após a definição da amostra, então, foi necessário elaborar o instrumento de pesquisa adotado - o questionário.

\subsubsection{Questionário - Elaboração e Aplicação}

Foi elaborado um questionário a fim de se obter as informações necessárias para o desenvolvimento do estudo. Na elaboração do questionário respectivo - de acordo com as técnicas apresentadas por Cooper e Schindler (2003) - foram utilizadas as escalas de classificação nas quais se solicita ao respondente posicionar cada fator em uma escala numérica.

Foram avaliados os prós e contras sobre a conveniência do desenvolvimento de um questionário com perguntas abertas, o que evitaria qualquer tipo de indução de pensamento, proporcionando riqueza maior de comentários, explicações e esclarecimentos, entretanto, conforme Mattar (1999) prescrevera, ela também apresenta desvantagens como o tempo de execução e custo elevado. Além desses aspectos, pode ser filtrado pela interpretação do entrevistador, o que representaria dificuldade grande para a tabulação e a codificação final. Assim, optou-se por perguntas fechadas, com a utilização de uma escala likert de 5 pontos. O questionário foi dividido, então, em quatro blocos distintos entre si. O primeiro visava a identificar e qualificar o entrevistado para possibilitar a construção de um perfil do grupo de entrevistados. O segundo bloco trazia perguntas com o objetivo explícito de identificar os motivadores estratégicos do processo de internacionalização da Vale, relacionando-os com os motivadores clássicos de internacionalização obtidos no processo de mapeamento da literatura, enquanto que o terceiro bloco relaciona as estratégias adotadas para o avanço da empresa no mercado internacional. No quarto bloco são pontuados os resultados obtidos pela empresa após a internacionalização.

Mattar (1999) enfatiza que o pré-teste consiste em saber como o questionário irá se comportar numa situação real de coleta de dados. O processo começou no dia 7 de maio de 2008. Na ocasião foi aplicado um questionário-piloto. Ao final da entrevista foram realizados os ajustes necessários com vistas à compreensão fluida e à aplicação aos demais entrevistados.

O contato inicial foi realizado por mensagem eletrônica (e-mail), que continha informações basilares como a condição de aluno-pesquisador - matriculado no programa de Mestrado Profissionalizante em Administração no IBMEC - o objetivo da pesquisa e da dissertação de mestrado, o processo de escolha pelo qual o respondente foi selecionado e os benefícios esperados desse processo. Esses trâmites foram seguidos, e reforçaram a importância da participação. Solicitou-se, por fim, que o entrevistado, em caso de resposta positiva, propusesse a data e o horário que melhor lhe conviesse para a realização dela. A maioria dos respondentes indicou a dificuldade de agenda para a realização da entrevista e, para eles assim como para respondentes de outros estados, foi oferecida a opção do envio do questionário por mensagem eletrônica e a posterior devolução, para as quais o pesquisador providenciou cópias comprobatórias. A pesquisa foi realizada entre os dias 8 e 29 de maio de 2008 .

\subsubsection{Tratamento e compilação dos dados}

Para o tratamento das informações na presente pesquisa, consideraram-se os blocos um a quatro em que se dividiram os questionários. As respostas foram tratadas em uma 
planilha do software Microsoft Excel, tendo cada questionário sido salvo no computador na ordem de recebimento.

\section{Revisão de Literatura}

\subsection{A globalização e as estratégias de internacionalização}

Globalização é um processo de integração mundial, que por sua amplitude e velocidade está afetando profundamente os indivíduos, as empresas e nações, pois altera os fundamentos sobre os quais se organizou a economia mundial nos últimos 50 anos (Bassi, 1999).

Para alguns autores, notadamente Bartlett (1992), as empresas procuram o mercado internacional para atender aos motivadores tradicionais como o desenvolvimento de uma fonte segura de suprimentos. Buscam, também, novos mercados e as possibilidades acenadas por cenários com custos baixos de produção em conjunto com os motivadores conhecidos por emergentes. Dentre eles, destaque para a economia de escopo, investimentos em pesquisa e a redução do ciclo de vida dos produtos, além da oportunidade de aprendizado global e do aumento do posicionamento competitivo.

Conforme a definição de Hitt et al (2001), as alternativas do modo de entrada podem se dar por exportação (direta ou indireta), contratual (licenciamento, franquia e acordos de cooperação) e ainda por investimento (greenfield - novo projeto ou brownfield - aquisição de um projeto já existente ou joint venture com um parceiro local).

Bartlett (1992) e Hitt et al (2001) afirmam que operar em um cenário internacional possibilita às empresas novas oportunidades e capacidade superior para compreender mercados, por permitir o acesso a novos cenários, aos recursos especializados bem como às novas fontes de informação e conhecimento.

De acordo com Ghoshal (1993), cada subsidiária de uma determinada empresa opera em um ambiente nacional diferente. Em cada país a subsidiária local deve estar receptiva a clientes, governos e órgãos reguladores locais, e conjugar as duas forças existentes, para receptividade nacional e para integração global, que não representam, em tese, extremidades opostas de um espectro. Embora sejam relacionadas, é possível considerá-las como dimensões separadas. Assim, uma empresa que não estiver preparada para enfrentar a receptividade nacional, não tem automaticamente força suficiente para alcançar a integração global e viceversa. Por exemplo, negócios como os produtos farmacêuticos, as telecomunicações e os computadores podem simultaneamente se deparar com demandas fortes tanto para integração global como para a receptividade local.

Resumindo os conceitos apresentados por Bartlett (1992), Beamish (2003), Ghoshal (1993), Hill (2005) e Hitt et al (2001), o autor apresenta de maneira sumarizada no quadro 1 os diferentes tipos de empresas internacionais. O quadro foi dividido em três partes para propiciar uma melhor análise e foi montada baseada na literatura nacional e internacional mencionada anteriormente. $\mathrm{Na} 1^{\mathrm{a}}$. parte está apresentada a orientação estratégica, ou seja a estratégia de entrada e o formato de atuação de cada tipo de empresa conforme a literatura. $\mathrm{Na}$ $2^{\mathrm{a}}$. parte está colocada a configuração dos ativos ou seja é feita uma análise de que forma a empresa optou por dispor seus ativos e recursos ao redor do globo. Finalizando, são apresentados os resultados obtidos por cada tipo de formação empresarial e o exemplo de algumas empresas que seguiram as respectivas formações. 


\begin{tabular}{|c|c|c|c|c|}
\hline & $\begin{array}{c}\text { Empresa } \\
\text { multinacional }\end{array}$ & $\begin{array}{c}\text { Empresa } \\
\text { internacional }\end{array}$ & $\begin{array}{c}\text { Empresa } \\
\text { global }\end{array}$ & $\begin{array}{c}\text { Empresa } \\
\text { transnacional }\end{array}$ \\
\hline $\begin{array}{l}\text { Orientação } \\
\text { estratégica }\end{array}$ & $\begin{array}{c}\text { Resposta às } \\
\text { preferências dos } \\
\text { consumidores locais, } \\
\text { baseada em recursos } \\
\text { e inovação local. } \\
\text { Fraca integração } \\
\text { global. } \\
\text { Foco no aumento da } \\
\text { receita. }\end{array}$ & $\begin{array}{c}\text { Explorando } \\
\text { conhecimento da } \\
\text { empresa-mãe pela } \\
\text { difusão e geração da } \\
\text { inovação. } \\
\text { Foco em criar e } \\
\text { explorar inovações } \\
\text { em base mundial. } \\
\text { Alavancar os ciclos } \\
\text { de vida dos produtos. }\end{array}$ & $\begin{array}{l}\text { Eficiência global e } \\
\text { estratégias de baixo } \\
\text { custo por } \\
\text { intermédio de } \\
\text { operações } \\
\text { centralizadas e } \\
\text { escala global. } \\
\text { Padronização de } \\
\text { produtos. }\end{array}$ & $\begin{array}{l}\text { Eficiência global, } \\
\text { flexibilidade e } \\
\text { aprendizado global } \\
\text { simultâneo. } \\
\text { Combinação de } \\
\text { eficiência, } \\
\text { flexibilidade com } \\
\text { resposta às } \\
\text { necessidades locais e } \\
\text { aprendizado } \\
\text { simultâneo. }\end{array}$ \\
\hline $\begin{array}{c}\text { Configura- } \\
\text { ção } \\
\text { dos } \\
\text { ativos } \\
\text { e } \\
\text { competên- } \\
\text { cias }\end{array}$ & $\begin{array}{c}\text { Ativos e recursos } \\
\text { dispersos permitindo } \\
\text { as subsidiárias } \\
\text { atividades de } \\
\text { desenvolvimento e } \\
\text { produção. } \\
\text { Permite atingir custos } \\
\text { e receitas numa base } \\
\text { de moeda a moeda de } \\
\text { cada país. }\end{array}$ & $\begin{array}{c}\text { Recursos } \\
\text { centralizados para } \\
\text { facilitar inovação. } \\
\text { Desenvolvimento de } \\
\text { inovações como fonte } \\
\text { de vantagens } \\
\text { competitivas. } \\
\text { Matriz da empresa } \\
\text { em países } \\
\text { tecnologicamente } \\
\text { avançados. }\end{array}$ & $\begin{array}{l}\text { Centralização dos } \\
\text { ativos no país-sede } \\
\text { ou países de baixo } \\
\text { custo e busca da } \\
\text { escala global. } \\
\text { Explora vantagens } \\
\text { da curva de } \\
\text { experiência. } \\
\text { Explora economias } \\
\text { por localização. }\end{array}$ & $\begin{array}{c}\text { Disperso, } \\
\text { interdependente e } \\
\text { especializada com } \\
\text { operação em países } \\
\text { de baixo custo e } \\
\text { pesquisa em países de } \\
\text { ponta. } \\
\text { Evita a dependência } \\
\text { de uma só região ou } \\
\text { país. }\end{array}$ \\
\hline Resultad & $\begin{array}{c}\text { Dificuldade no } \\
\text { compartilhamento de } \\
\text { conhecimento e } \\
\text { competências de } \\
\text { outras unidades. } \\
\text { Inabilidade em } \\
\text { realizar economias } \\
\text { por localização. } \\
\text { Falhas para explorar } \\
\text { vantagens dos efeitos } \\
\text { da curva de } \\
\text { experiência. }\end{array}$ & $\begin{array}{c}\text { Falta de } \\
\text { responsividade local. } \\
\text { Transfere novos } \\
\text { produtos e estratégias } \\
\text { para subsidiárias. } \\
\text { Centralização do } \\
\text { desenvolvimento de } \\
\text { produtos na origem. } \\
\text { País-sede mantém } \\
\text { controle sobre a } \\
\text { produção e a } \\
\text { comercialização. }\end{array}$ & $\begin{array}{l}\text { Falta de respostas } \\
\text { no espectro local. } \\
\text { Mundo visto como } \\
\text { unidade de análise } \\
\text { singular, com } \\
\text { produtos vendidos } \\
\text { de forma similar. } \\
\text { Sistema eficiente e } \\
\text { centralizado, com } \\
\text { operações } \\
\text { gerenciadas } \\
\text { centralmente. }\end{array}$ & $\begin{array}{l}\text { Explora vantagens da } \\
\text { curva de experiência. } \\
\text { Explora economias } \\
\text { por localização. } \\
\text { Incerteza quanto a } \\
\text { disponibilidade de } \\
\text { matérias-primas, } \\
\text { capital e pessoas. } \\
\text { Necessidade de } \\
\text { responder à demanda } \\
\text { global competitiva } \\
\text { simultaneamente. }\end{array}$ \\
\hline $\begin{array}{l}\text { Exemplos } \\
\text { de } \\
\text { empresas }\end{array}$ & $\begin{array}{c}\text { Unilever, Philips e } \\
\text { Nestlé }\end{array}$ & $\begin{array}{l}\text { IBM, Kellogs, Wal } \\
\text { Mart e McDonald's }\end{array}$ & $\begin{array}{l}\text { Toyota, Canon, } \\
\text { Komatsu e } \\
\text { Matsushita }\end{array}$ & $\begin{array}{c}\text { Embraer, GE Medical } \\
\text { System, Lenovo e } \\
\text { Gazprom }\end{array}$ \\
\hline
\end{tabular}

Quadro 1 - Modelo de Atuação das Empresas.

Bartlett (1992) afirma que a partir da década de 1980 cada vez mais as empresas estão sendo demandadas simultaneamente por eficiência global, resposta local e inovação mundial e que essas questões estão cada vez mais complexas, o que as leva a buscar um modelo transnacional de ação, pois se torna difícil sustentar a competitividade baseando-se somente em competência única. Elas precisarão, assim, desenvolver a capacidade de responder a todos os fatores ao mesmo tempo sem desconsiderar preterir um deles sequer. Mais do que alcançar economias de escala por intermédio da centralização e padronização da produção, as empresas devem construir eficiência global por intermédio de uma estrutura mundial de ativos especializados e de competências que explorem as vantagens comparativas, economias de escala e economias de escopo simultaneamente.

Beamish (2003) complementa que as empresas transnacionais oferecem maior autonomia às afiliadas em comparação às empresas globais, apesar de elas permanecerem integradas à estratégia única. As iniciativas começam tanto nas afiliadas quanto na sede, e todo o relacionamento entre as filiais é incentivado. Mais do que funcionar como uma hierarquia, as organizações transnacionais funcionam como uma rede de tomada de decisões Menezes, J. D. C.; Campos Filho, L. A. N. 
horizontais, visando à maximização de eficiência, resposta local e aprendizado organizacional. Bartlett (1992) ratifica ao afirmar que uma verdadeira transnacional atua como um disseminador das melhores práticas ao fazer com que todas as filiais funcionem como fonte de competências, experiências e inovação que podem ser facilmente transferidas de um país para outro, o que fortaleceria toda a organização.

Para Garrido et al (2006), após a decisão de se internacionalizar, uma empresa deve escolher sua estratégia e modelo de entrada e o arranjo institucional necessário ao transferir para o mercado os produtos, as tecnologias, as habilidades humanas, o gerenciamento ou outros recursos. Essa decisão deve levar em consideração os aspectos do mercado-alvo, tais como atratividade, tamanho, crescimento, competição, distância e acessibilidade, bem como aspectos da empresa divididos em recursos, filosofia e objetivos (Whitelock, 2002).

\subsubsection{Modelo de internacionalização das empresas americanas, européias e japonesas}

Conforme Bartlett (1992) e Hill (2005), as empresas européias tais como Unilever, ICI, Philips e Nestlé, quando da definição do modelo para entrada em mercados internacionais, respeitaram o modelo de empresa multinacional, por haver o privilégio à resposta das demandas locais dentro dos países onde atua. $\mathrm{O}$ fator-chave diferenciador para as empresas adeptas da estratégia multinacional é que elas customizam tanto a oferta e características do produto, bem como as respectivas estratégias de marketing para adequar-se às demandas locais. Nessas empresas, ativos e recursos foram historicamente dispersos, por permitir às subsidiárias a empreender espectro preponderante de atividades, do desenvolvimento e produção às unidades de vendas e serviços, com ampla autonomia. Com isso, costumam estabelecer um conjunto completo de atividades visando à criação de valor que inclui produção, marketing, pesquisa e desenvolvimento nos principais mercados em que atuam, com a tendência a desenvolver uma estrutura de custos maiores devido à duplicação dessas estruturas. A estratégia multinacional faz mais sentido quando existem fortes pressões para o nível de resposta local e baixas pressões para a redução de custos (Hill, 2005).

Já as empresas americanas como Kraft, Procter \& Gamble, McDonald's, IBM, WalMart, Microsoft e General Eletric, segundo Bartlett (1992), optaram por seguir o modelo de empresa internacional, com o foco na criação e exploração de inovação em base mundial, por transferir produtos, processos e estratégias desenvolvidas no país de origem para as unidades menos avançadas, entretanto vale ressaltar a posição de Yip (1989) que afirma que essa estratégia resulta em produtos que não podem satisfazer todas as necessidades em todos os países. Isso aconteceria por não haver a adaptação necessária às preferências locais, que geraria no segundo momento a perda de participação no mercado. A tendência é a de centralizar as funções de desenvolvimento de produto no país-sede, por manter as funções de produção e marketing em poucos países nos quais atuam, teriam - como resultado - a manutenção dos demais controles sobre essas funções. A forma de atuação destas empresas também apresenta pontos em comum com a teoria do ciclo do produto em um novo ambiente internacional de Vernon (1979).

A estratégia internacional faz sentido se a empresa atua com a competência central valiosa que os competidores locais não têm, e se a empresa enfrenta baixa pressão local por responsividade e redução de custos. Quando as pressões por responsividade local, entretanto, são altas, as firmas adeptas dessa estratégia geralmente perdem participação de mercado para as que conseguem customizar os produtos aos clientes (Hill, 2005).

Contrário às estratégias adotadas pelas companhias americanas e européias, as empresas japonesas como Toyota, Canon, Komatsu e Matsushita adotaram a estratégia global, ao primarem pelo desenvolvimento de uma eficiência global das operações. Essas operações, entretanto, apesar do ganho de eficiência que produzem, comprometem a flexibilidade e o 
processo de aprendizado, não capturando o conhecimento gerado nas demais unidades (Bartlett, 1992). Essas empresas - de acordo com o pensamento de Yip (1989) e Ohmae (1989) - têm como um dos focos a redução dos custos das operações e a qualidade melhorada dos produtos.

Empresas que seguem a estratégia global objetivam o aumento da lucratividade pela estratégia da redução de custos. As funções de produção, marketing, pesquisa e desenvolvimento são concentradas em países que ofereçam as melhores condições. As corporações, assim, não customizam o produto e as estratégias de marketing, preferem vender um produto padronizado para todo o mundo, a fim de que possam usufruir dos máximos benefícios das economias de escala. Para isso, utilizam o custo baixo para suportar ações agressivas de preços dos concorrentes. Essa estratégia faz mais sentido quando existem pressões para a redução de custos e onde as demandas por responsividade local são mínimas. De uma forma incremental, essas condições têm prevalecido com sucesso em vários segmentos como na indústria dos semicondutores por empresas como Intel e Motorola, e não são encontrados nas indústrias de bens de consumo nas quais as demandas por responsividade local permanecem altas (Hill, 2005).

\subsubsection{As BRICS e o modelo de internacionalização}

BRIC (acrônimo criado para Brasil, Rússia, Índia e China) sintetiza a reunião de países emergentes que - segundo os especialistas de comércio internacional e mercado financeiro - em virtude do vigor de suas economias tem propensão para alcançar grandes players internacionais, com uma estimativa de que no ano de 2050 estas quatro economias somadas podem ser maior do que soma das economias do G6 (Estados Unidos, Japão, Alemanha, França, Itália e Reino Unido), medidas em dólares americano. (Goldman Sachs, 2007)

Conforme estudo recente realizado entre empresas latino-americanas que estão iniciando o caminho da internacionalização (Booz Allen, 2007), as empresas da região, além de possuírem motivadores similares como o acesso a novos mercados e matérias-primas, reduções de custo de capital e custos de produção - além da redução do risco cambial também apresentam estratégias similares, na maioria dos casos, fortalecem a posição no mercado doméstico e depois replicam o sucesso da estratégia empregada no país-sede.

Segundo o estudo da Booz Allen (2007), outra estratégia é alavancar vantagem competitiva por intermédio das matérias-primas existentes no país-sede. Pode-se verificar que três estágios são marcantes no processo de governança visando à internacionalização:

- Estágio inicial - Presença forte no país-sede com foco na exportação e produtividade elevada dos ativos e menos de $10 \%$ da receita advinda das operações internacionais;

- Estágio intermediário - Internacionalização regional e produtividade dos ativos em toda a região e de $10 \%$ a $40 \%$ da receita total advindas das operações internacionais;

- Estágio avançado - Internacionalização global, com ativos distribuídos nos mais relevantes mercados do segmento e mais de $40 \%$ das receitas advindas das operações internacionais.

A associação entre Valverde (2006), UNCTAD (2007) e o estudo da BCG (2008) possibilita demonstrar que os países do BRIC utilizam intensivamente recursos naturais oriundos dos membros constitutivos como base de inserção comercial. Produtos agrícolas e minerais no Brasil, petróleo e gás natural na Rússia, produtos têxteis na Índia e China são exemplos dessa estratégia de internacionalização. 


\subsubsection{Comparação dos modelos de internacionalização}

Dessa forma, baseado nas seções anteriores e para organizar o pensamento, foi possível ao produzir os quadros comparativos 2 a 4 , ao relacioná-los com os motivadores, estratégias e resultados processados pelas empresas européias, americanas, japonesas e países do BRIC. Os quadros mencionados foram construídos utilizando os conceitos de Bartlett (1992), Beamish (2003), Ghoshal (1993), Hill (2005) e Hitt et al (2001) e também os estudos desenvolvidos pela Booz-Allen (2007), BCG (2008) e UNCTAD (2007). O quadro 2 realiza a comparação dos motivadores para internacionalização das empresas européias, americanas, japonesas e países do BRIC.

\begin{tabular}{|c|c|c|c|c|}
\hline & $\begin{array}{l}\text { Empresas } \\
\text { européias }\end{array}$ & $\begin{array}{c}\text { Empresas } \\
\text { americanas }\end{array}$ & $\begin{array}{l}\text { Empresas } \\
\text { japonesas }\end{array}$ & $\begin{array}{c}\text { Empresas dos } \\
\text { BRICs }\end{array}$ \\
\hline \multirow{5}{*}{$\begin{array}{l}\text { Motivado- } \\
\text { res }\end{array}$} & & $\begin{array}{l}\text { Expansão baseada } \\
\text { na busca pelo } \\
\text { aumento do volume } \\
\text { da produção. }\end{array}$ & $\begin{array}{l}\text { Pequeno mercado } \\
\text { no país de origem } \\
\text { da empresa. }\end{array}$ & $\begin{array}{l}\text { Vantagem competitiva } \\
\text { relacionada à extração } \\
\text { de commodities. }\end{array}$ \\
\hline & $\begin{array}{c}\text { Levar produtos } \\
\text { existentes para } \\
\text { mercados externos. }\end{array}$ & $\begin{array}{c}\text { Novos mercados } \\
\text { para fortalecer } \\
\text { negócio (margem e } \\
\text { volume). }\end{array}$ & $\begin{array}{l}\text { Desenvolvimento } \\
\text { de novas fontes } \\
\text { seguras de } \\
\text { suprimento. }\end{array}$ & $\begin{array}{l}\text { Novos mercados para } \\
\text { fortalecer o negócio } \\
\text { (margem e volume). }\end{array}$ \\
\hline & $\begin{array}{l}\text { Forte pressão para a } \\
\text { responsividade local } \\
\text { e baixa pressão para } \\
\text { redução de custos }\end{array}$ & $\begin{array}{l}\text { Baixa pressão local } \\
\text { para a } \\
\text { responsividade e } \\
\text { redução de custos. }\end{array}$ & $\begin{array}{l}\text { Baixa pressão local } \\
\text { para a } \\
\text { responsividade e } \\
\text { forte pressão para a } \\
\text { redução de custos. }\end{array}$ & $\begin{array}{l}\text { Assegurar acesso em } \\
\text { longo prazo a fontes } \\
\text { de matérias-primas. }\end{array}$ \\
\hline & $\begin{array}{c}\text { Aumentar a } \\
\text { capacidade de } \\
\text { aprendizado em uma } \\
\text { escala global. }\end{array}$ & $\begin{array}{c}\text { Maximizar o } \\
\text { investimento em } \\
\text { pesquisa para } \\
\text { alavancar a } \\
\text { inovação }\end{array}$ & $\begin{array}{l}\text { Redução dos custos } \\
\text { de operação por } \\
\text { intermédio da } \\
\text { eficiência global e } \\
\text { da escala global. }\end{array}$ & $\begin{array}{c}\text { Maximizar } \\
\text { investimento feito em } \\
\text { pesquisa e } \\
\text { desenvolvimento. }\end{array}$ \\
\hline & $\begin{array}{l}\text { Oportunidade de } \\
\text { prospecção regional, } \\
\text { haja vista a homoge- } \\
\text { neidade dos consumi- } \\
\text { dores da região }\end{array}$ & $\begin{array}{l}\text { Procura por países } \\
\text { de baixo custo para } \\
\text { aperfeiçoar a } \\
\text { produção. }\end{array}$ & & \\
\hline
\end{tabular}

Quadro 2 - Comparação dos motivadores para internacionalização das empresas européias, americanas, japonesas e países do BRIC.

De acordo com o quadro 2, percebe-se, assim, que os motivadores para a internacionalização foram distintos entre as empresas americanas, européias, japonesas e países do BRIC, pois compreendem épocas e realidades geográficas e econômicas distintas. Esse movimento de internacionalização começou na Europa no início do século XX, caracterizado principalmente pelo movimento de expansão nos demais países da região, seguido do Japão no período do pós-guerra, em razão da necessidade de reconstrução econômica e do acesso a novas fontes de matérias-primas, e posteriormente, seguido pelas empresas americanas nas décadas de 1950 e 1960. Somente no final da década de 1980 e início da década de 1990 as empresas dos países-membro do BRIC efetivamente iniciaram o movimento de internacionalização.

O quadro 3 realiza a comparação das estratégias empregadas no processo de internacionalização das empresas européias, americanas, japonesas e países do BRIC. 


\begin{tabular}{|c|c|c|c|c|}
\hline & $\begin{array}{l}\text { Empresas } \\
\text { européias }\end{array}$ & $\begin{array}{c}\text { Empresas } \\
\text { americanas }\end{array}$ & $\begin{array}{l}\text { Empresas } \\
\text { japonesas }\end{array}$ & $\begin{array}{c}\text { Empresas dos } \\
\text { BRICs }\end{array}$ \\
\hline \multirow{7}{*}{$\begin{array}{l}\text { Estratégias } \\
\text { adotadas }\end{array}$} & $\begin{array}{c}\text { Construção de } \\
\text { diferenciação para } \\
\text { atender à demanda } \\
\text { local dos } \\
\text { consumidores. }\end{array}$ & $\begin{array}{l}\text { Foco na criação e } \\
\text { exploração da } \\
\text { inovação em base } \\
\text { mundial. }\end{array}$ & $\begin{array}{l}\text { Diminuição do } \\
\text { ciclo de vida dos } \\
\text { produtos, que } \\
\text { permite constante } \\
\text { lançamento de } \\
\text { produtos. }\end{array}$ & $\begin{array}{l}\text { Replicar o sucesso da } \\
\text { estratégia empregada } \\
\text { no país-sede. }\end{array}$ \\
\hline & $\begin{array}{c}\text { Estratégias de } \\
\text { prospecção regional, } \\
\text { haja vista a } \\
\text { homogeneidade dos } \\
\text { clientes da região. }\end{array}$ & $\begin{array}{l}\text { Produto padrão } \\
\text { comercializado da } \\
\text { mesma forma em } \\
\text { todo o mundo. }\end{array}$ & $\begin{array}{l}\text { Desenvolvimento } \\
\text { de produtos de alto } \\
\text { valor agregado e } \\
\text { padronização } \\
\text { através dos países. }\end{array}$ & $\begin{array}{l}\text { Transferência de } \\
\text { produtos, processos e } \\
\text { estratégias do país de } \\
\text { origem para as } \\
\text { unidades externas. }\end{array}$ \\
\hline & $\begin{array}{l}\text { Distribuição global } \\
\text { de ativos e recursos. }\end{array}$ & $\begin{array}{l}\text { Transferência de } \\
\text { produtos e } \\
\text { estratégias do país } \\
\text { de origem para as } \\
\text { unidades externas. }\end{array}$ & $\begin{array}{c}\text { Desenvolvimento } \\
\text { de produto focado } \\
\text { nas similaridades } \\
\text { internacionais em } \\
\text { vez das diferenças } \\
\text { culturais. } \\
\end{array}$ & $\begin{array}{c}\text { Estratégias de } \\
\text { prospecção regional } \\
\text { haja vista a } \\
\text { homogeneidade da } \\
\text { região - MERCOSUL. }\end{array}$ \\
\hline & $\begin{array}{l}\text { Inovação local por } \\
\text { intermédio da } \\
\text { concessão de } \\
\text { autonomia para as } \\
\text { subsidiárias. } \\
\end{array}$ & $\begin{array}{l}\text { Centralização do } \\
\text { desenvolvimento de } \\
\text { produto que } \\
\text { propicie ação local } \\
\text { de marketing. } \\
\end{array}$ & $\begin{array}{l}\text { Investimento em } \\
\text { amplo sistema de } \\
\text { distribuição. }\end{array}$ & $\begin{array}{l}\text { Forte investimento na } \\
\text { aquisição de empresas } \\
\text { de outros países. }\end{array}$ \\
\hline & $\begin{array}{l}\text { Foco no aumento da } \\
\text { receita. }\end{array}$ & & $\begin{array}{c}\text { Aumento da } \\
\text { lucratividade pela } \\
\text { redução de custos. }\end{array}$ & $\begin{array}{c}\text { Assumir a liderança } \\
\text { global da categoria na } \\
\text { qual atua. }\end{array}$ \\
\hline & $\begin{array}{l}\text { Foco no aumento da } \\
\text { competição dentro de } \\
\text { cada país. }\end{array}$ & & & $\begin{array}{l}\text { Monetarização dos } \\
\text { recursos naturais do } \\
\text { país-sede e } \\
\text { aproveitamento do } \\
\text { baixo custo } \\
\text { doméstico. }\end{array}$ \\
\hline & $\begin{array}{c}\text { Atua no modelo de } \\
\text { empresa } \\
\text { multinacional. }\end{array}$ & $\begin{array}{c}\text { Atua no modelo de } \\
\text { empresa } \\
\text { internacional. }\end{array}$ & $\begin{array}{l}\text { Atua no modelo de } \\
\text { empresa global. }\end{array}$ & $\begin{array}{c}\text { Tornar as marcas } \\
\text { globais. }\end{array}$ \\
\hline
\end{tabular}

Quadro 3 - Comparação das estratégias adotadas pelas empresas européias, americanas, japonesas e países do BRIC no processo de internacionalização.

Conforme o quadro 3, assim como os motivadores estratégicos foram distintos entre as empresas, as estratégias de internacionalização adotadas pelas empresas americanas, européias, japonesas e países do BRIC também mostram diferenças conceituais, de objetivos e de intensidade entre si. Dessa maneira, umas optam pela diferenciação para atender à demanda local e as empresas americanas optaram por uma consolidação de produtos em base mundial.

O quadro 4 apresenta a comparação dos resultados obtidos no processo de internacionalização das empresas européias, americanas, japonesas e países do BRIC. 


\begin{tabular}{|c|c|c|c|c|}
\hline & $\begin{array}{l}\text { Empresas } \\
\text { européias }\end{array}$ & $\begin{array}{c}\text { Empresas } \\
\text { americanas }\end{array}$ & $\begin{array}{l}\text { Empresas } \\
\text { japonesas }\end{array}$ & $\begin{array}{c}\text { Empresas dos } \\
\text { BRICs }\end{array}$ \\
\hline \multirow{4}{*}{$\begin{array}{l}\text { Resultados } \\
\text { alcançados }\end{array}$} & $\begin{array}{c}\text { Ineficiência para } \\
\text { explorar o } \\
\text { conhecimento e } \\
\text { competência gerados } \\
\text { por unidades } \\
\text { internacionais. } \\
\end{array}$ & $\begin{array}{l}\text { Falta de sistema de } \\
\text { distribuição forte. }\end{array}$ & $\begin{array}{l}\text { Comprometimento } \\
\text { do aprendizado, por } \\
\text { não internalizar o } \\
\text { conhecimento } \\
\text { gerado nas demais } \\
\text { unidades. }\end{array}$ & $\begin{array}{c}\text { Amplo esforço de } \\
\text { ampliação do portfólio } \\
\text { de produtos e países. }\end{array}$ \\
\hline & $\begin{array}{c}\text { Fraca integração } \\
\text { global. }\end{array}$ & $\begin{array}{l}\text { Sem adaptação } \\
\text { local que leva à } \\
\text { perda de market } \\
\text { share. }\end{array}$ & $\begin{array}{l}\text { Sem resposta às } \\
\text { demandas locais. }\end{array}$ & $\begin{array}{l}\text { Maior influência das } \\
\text { empresas no comércio } \\
\text { internacional. }\end{array}$ \\
\hline & $\begin{array}{c}\text { Não alcança } \\
\text { economia de escala, o } \\
\text { que implica em } \\
\text { custos mais altos. }\end{array}$ & $\begin{array}{l}\text { Deficiência em } \\
\text { atingir a escala } \\
\text { global. }\end{array}$ & $\begin{array}{l}\text { Vulnerabilidade da } \\
\text { competição baseada } \\
\text { nas vantagens de } \\
\text { custo de mão-de- } \\
\text { obra e escala. }\end{array}$ & $\begin{array}{c}\text { Criar equipes } \\
\text { gerenciais capazes de } \\
\text { enfrentar desafios } \\
\text { ligados à globalização. }\end{array}$ \\
\hline & & & $\begin{array}{c}\text { Focaliza na } \\
\text { economia de escala }\end{array}$ & $\begin{array}{c}\text { Desenvolver } \\
\text { conhecimento em } \\
\text { fusão e aquisição. }\end{array}$ \\
\hline $\begin{array}{c}\text { Exemplos } \\
\text { de empresas }\end{array}$ & $\begin{array}{l}\text { Unilever, Philips e } \\
\text { Nestlé }\end{array}$ & Kraft, Pfizer e GE & $\begin{array}{c}\text { Toyota, Canon, } \\
\text { Komatsu e } \\
\text { Matsushita } \\
\end{array}$ & $\begin{array}{c}\text { Vale e Embraer, } \\
\text { Lenovo, India - Wipro } \\
\text { e Gazprom }\end{array}$ \\
\hline
\end{tabular}

Quadro 4 - Comparação dos resultados obtidos pelas empresas européias, americanas, japonesas e países do BRIC no processo de internacionalização.

Baseado no quadro 4, verifica-se que os resultados e problemas enfrentados, assim como os que foram demonstrados nos quadros anteriores de motivadores e estratégias são diferentes entre si, e mantêm relação com os respectivos desafios iniciais.

\section{O Mercado Mundial de Mineração}

O objetivo desta seção é apresentar um breve histórico do mercado mundial de mineração e a evolução da internacionalização das empresas BHP Billiton, Rio Tinto e Vale.

\subsection{Contextualização}

O mercado de mineração e metais é caracterizado por investimentos de longo prazo, acentuada dispersão geográfica e intensivo em capital vem sendo impulsionado por resultados consistentes de crescimento da economia mundial nos últimos anos. Entre as principais motivações para a internacionalização do mercado de mineração, podemos encontrar relação com os motivadores da escola americana, com destaques à expansão baseada na busca pelo aumento do volume de produção, à busca por novos mercados para fortalecer o negócio existente e à procura pela maximização do investimento feito em pesquisa e desenvolvimento. A matéria-prima principal desse setor é o minério de ferro, utilizado intensamente na construção e na fabricação de aço, e que apresentou crescimento expressivo nos últimos anos. Enfim, o setor registrou praticamente o dobro da produção entre os anos de 1998 e 2006, impulsionado, principalmente, pela economia chinesa (Macquarie Research, 2006).

O rearranjo na mineração mundial é devido pela ampliação do controle do mercado e, ainda, pela busca de sinergia e diversificação. No primeiro caso as empresas aumentam a participação em segmentos nos quais atuam e buscam sinergias operacionais, enquanto que o segundo objetivo é o de reduzir a dependência de um mineral ou de um país em particular, motivado pela diversificação, embora com atuação no âmbito da mineração. Todo esse crescimento levou a um movimento de aquisições e fusões sem precedentes, além da 
diversificação do portfólio de produtos e países das empresas (Exame, 2006), no qual as 5 principais empresas do setor registraram capitalização de mercado de USD 754 milhões, conforme apresentado na tabela 1.

\begin{tabular}{c|c|c|c} 
& Empresa & País & $\begin{array}{c}\text { Capitalização de Mercado } \\
\text { (USD bilhöes) }\end{array}$ \\
\hline 1 & BHP BIILLITON & Austrália/ R.Unido & $\mathbf{2 3 5 , 0 3 7}$ \\
\hline 2 & VALE & Brasil & $\mathbf{1 8 5 , 6 7 1}$ \\
\hline 3 & RIO TINTO & Reino Unido & $\mathbf{1 6 5 , 2 8 8}$ \\
\hline 4 & ANGLO AMERICAN & Reino Unido & $\mathbf{8 7 , \mathbf { 8 4 2 }}$ \\
\hline 5 & XSTRATA & Suiça & $\mathbf{8 0 , 4 1 9}$ \\
\hline
\end{tabular}

Tabela 1 - Classificação das principais empresas de mineração e metais classificados pelo valor de capitalização de mercado em 12 de maio de 2008.

Fonte: Bloomberg

Para não perder as oportunidades oferecidas por um cenário de demanda vigorosa por produtos e aumento de preços, as empresas de mineração estão diversificando os portfólios de produção, solidificando a presença internacional e a expansão das atividades.

\subsection{Estratégias de internacionalização do segmento de mineração}

\subsubsection{BHP Billiton}

Em junho de 2001, surge a mineradora australiana BHP Billiton, com base na fusão da Billiton PLC e da BHP Limited, duas empresas centenárias. Elas foram constituídas como dual listed companies (DLC), ou seja, as empresas continuaram a existir juridicamente em separado com registros em bolsas separadas, mas são administradas como empresa única e por diretoria executiva única. A Billiton, do Reino Unido, foi fundada em 1860 e 23 anos depois, em 1883, foi criada a BHP, com sede na Austrália. Na época da fundação, entretanto, os principais ativos da BHP e Billiton estavam na Indonésia e no escritório central dela. Para examinar a trajetória recente da empresa, é necessário analisar separadamente a história recente da BHP e da Billiton, notadamente o período anterior a 2001. Em março de 2001, fundir-se a BHP com vistas a reduzir a dependência das duas empresas em um portfólio exíguo de minerais e de países, gerando a maior operação já realizada no setor até aquela época, estimada em USD 14,5 bilhões, valor que propiciou à empresa contar com um portfólio amplo de produtos. A orientação global da empresa pode ser percebida pela diversificada exposição geográfica, tanto em relação aos mercados consumidores quanto aos produtores (BHP, 2008).

Em 2008, a empresa atingiu o valor de mercado de US\$ 235 bilhões. Ela hoje está presente em 25 países e detém portfólio de mais de 24 commodities, o que a transforma, assim, em corporação sempre preparada para atender à demanda elevada em nível mundial por diversos tipos de metais. Durante os dois últimos meses de 2007 e o primeiro trimestre de 2008, a BHP fez uma oferta de USD 150 bilhões para a compra da mineradora Rio Tinto. Unidas, as empresas passariam a ter o controle total sobre o minério de ferro, o carvão e o cobre extraídos de 154 minas ao redor do mundo. Isso representaria à nova empresa o controle sobre $40 \%$ do suprimento mundial de minério de ferro. As negociações, entretanto, foram encerradas sem êxito (Valor Econômico, 2008). 


\subsubsection{Rio Tinto}

A Rio Tinto, empresa anglo-australiana com sede no Reino Unido, teve origem no sul da Espanha, com base em uma antiga mina que abastecia o império Romano. Em 1873, a empresa Rothschild \& Sons, de Londres, e a Rothschild Frères, de Paris, juntaram-se a outros investidores para adquirir do governo espanhol essas minas até então deficitárias. A empresa é, dessa maneira, formada pela fusão da Rio Tinto PLC, sociedade anônima, baseada no Reino Unido, e da Rio Tinto Limited registrada na Bolsa de Valores australiana. A companhia está presente em mais de 15 países, porém com forte representação na Austrália e na América do Norte, e ainda com atividades significativas na América do Sul, Ásia, Europa e no sul da África.

A evolução da Rio Tinto, de 1996 até 2006, foi marcada pela aquisição de negócios, por investimentos em novos campos de mineração e pela expansão dos empreendimento antigos. Entre as decisões mais relevantes, destaque para a aquisição, em 1997, de reservas adicionais de carvão nos EUA. Em 2000, a empresa investiu USD 4 bilhões em aquisições de grandes reservas de aluminio, minério de ferro, diamantes e carvão. A corporação está presente ainda em projetos na Austrália, Canadá e Brasil. Além disso, há investimentos em minas na África do Sul e em demais países da América do Sul (Macquarie Research, 2006). Em 2008, o valor de mercado da Rio Tinto está estimado em USD 165,2 bilhões (Bloomberg) contra aproximadamente USD 21 bilhões em 1996, com a participação de $23 \%$ no mercado transoceânico de minério de ferro.

\subsubsection{Vale: Uma transnacional verde e amarela}

No início da década de 1940, o Brasil fez a opção por transformar-se em um país moderno e industrializado. A nação abandonou as práticas essencialmente agrárias e monocultoras que a legavam ao atraso em relação ao mundo. Visando o fortalecimento desta transformação, foi tomada uma decisão política no sentido de desvincular o problema da instalação da siderurgia da questão da exploração do minério de ferro. Isso aconteceu por intermédio da criação de duas organizações estatais distintas: a CSN e a Vale. Os conflitos de interesse haviam se estendido durante toda a primeira metade do século XX e, na conjuntura da Segunda Guerra, foram resolvidos graças a acordos entre Brasil, Estados Unidos e Inglaterra, conhecidos como Acordos de Washington, assinados em 1942. Desta forma o Presidente Getúlio Vargas, por meio do Decreto-Lei $n^{\circ}$. 4.352, de $1^{\circ}$. de junho de 1942 , criou as bases para a estruturação de uma empresa para mineração e exportação do minério de ferro brasileiro (Zorzal e Silva, 2001). Os anos 60, caracterizaram a etapa de integração vertical e de implantação da logística de longa distância, bem como dos primeiros contratos de longo prazo com as empresas japonesas de siderurgia - Yawata, Fuji, Nippon Kokan, Kawasaki, Sumitomo, Kobe, Nisshin e Nakayama (Zorzal e Silva, 2001).

Em 1997, após o processo de privatização, a companhia foi adquirida por um consórcio de empresas lideradas pela Companhia Siderúrgica Nacional (CSN), no valor de USD 3,3 bilhões, durante o leilão realizado na Bolsa de Valores do Rio de Janeiro, na qual foram adquiridos $41,73 \%$ das ações ordinárias do Governo Federal. O valor total de mercado à época foi avaliado em USD 10 bilhões. Fora do controle estatal, a empresa se lança de maneira estruturada e vigorosa em busca de novos mercados para os produtos e expansão das operações. Apesar de em 1997 a empresa já exportar minério para vários países, a Vale não possuía ativos fora do território brasileiro. Em julho de 2000, ao dar início ao processo de exposição global, as ações da Vale passaram a ser listadas na Bolsa de Valores de Nova Iorque (NYSE) e na LATIBEX - Bolsa Eletrônica de Madri, fatos que a consagraram efetivamente como empresa global. 
Em 2001, após estudos de mercado e análise de cenários, a empresa adotou um planejamento estratégico simples, e que não chamou a atenção na época, pois a indústria de mineração era vista como uma indústria em declínio, mas que seguido à risca iria mudar a sua história: tornar-se a empresa líder mundial na produção de metais. Dessa forma, a companhia passou a comprar empresas no Brasil, e principalmente no exterior para suprir as deficiências no portfólio como níquel e cobre (Valor Econômico, 2008). A Vale baseou a estratégia em seis principais motivadores estratégicos para o processo de internacionalização:

1. Desempenho da empresa dependia de um único produto (minério de ferro), enquanto havia demanda mundial crescente por diversos tipos de metais;

2. Desempenho da empresa estava atrelado principalmente ao crescimento econômico e à demanda da economia chinesa;

3. A empresa possuía ativos somente no Brasil. Isso dificultava o processo de aprendizado de novas tecnologias;

4. Necessidade de maior exposição internacional, pois o risco da empresa estava atrelado ao risco - Brasil, que impunha custo de capital desfavorável à empresa;

5. Empresa que por ser considerada de atuação regional possuía baixo poder de negociação perante o mercado;

6. Baixo valor de mercado incompatível com a qualidade e quantidade das reservas e do desempenho da empresa.

De maneira geral o processo de internacionalização foi realizado de forma combinada por intermédio de aquisições de empresas já existentes ou em processo de implantação projetos brownfield - ou por meio de exploração mineral - projetos greenfield - que caracterizam investimentos em novos projetos. No período de 1996 a 2006, a Vale realizou expansões internacionais - projetos brownfield - no Bahrein (GIIC), em 2000, Noruega (Mo I Rana), em 2003 e no Canadá, na Caniço e Inco, em 2005 e 2006 respectivamente. Em 2007, ela adquiriu a AMCI Holdings Austrália Pty que opera e controla ativos de carvão em diversos países.

Após adquirir por USD 19 bilhões a mineradora canadense Inco - empresa que possui as maiores reservas mundiais de níquel -, em outubro de 2006, é que a Vale passou a incrementar significativamente o valor de mercado dela, passando a ter, em 2008, um valor de mercado de USD 185,6 bilhões (Bloomberg, 2008). Quando comparado com o valor de privatização, verifica-se que a Vale obteve crescimento de 61 vezes no valor de mercado durante o período que compreende os anos de 1997 a 2008. Em 2008, a Vale está presente em 31 países, além de 14 estados brasileiros. Um dos pontos fortes da empresa é o crescimento diversificado das atividades de mineração, com investimentos em programas de pesquisa geológica e de exploração de recursos minerais em diversos países.

Uma frase que resume o conceito de gestão internacional empregado pela Vale no período analisado foi proferida pelo presidente Roger Agnelli, em outubro de 2006:

"Onde pudermos achar perspectiva de crescimento vamos analisar investimentos e aquisições; fizemos várias em cinco anos e vamos continuar nesse ritmo procurando adquirir ativos de qualidade e vida longa e que traga sinergia e presença em novos mercados como é o caso da Inco". (Gazeta Mercantil, 2006).

Bartlett (1992) afirma que a vantagem das empresas transnacionais está na capacidade de trabalhar de forma equilibrada na busca por eficiência, aprendizado e inovação. A Vale vem demonstrando extrema habilidade na implantação da estratégia internacional. Faz isso ao mesclar projetos greenfield e brownfield, e ampliar para 31 países a participação efetiva da companhia. Ganhos de sinergia foram observados pela Vale na decisão de adquirir algumas 
empresas e, em particular, a canadense Inco. O motivo para essa intensificação da estratégia se justifica, pois as grandes concorrentes - BHP Billiton e Rio Tinto - já apresentavam perfil de exploração mais homogêneo e de exposição a mercados de forma mais pulverizada. Dessa forma, a empresa optou por atitudes mais agressivas, que a fizeram diminuir a desvantagem competitiva.

Com a adoção dessa estratégia de gestão internacional, a Vale alcançou o $64^{\circ}$ lugar no índice de transnacionalidade medido pelo UNCTAD (2007), que é um índice calculado pelas médias da participação relativa em ativos no exterior, número de funcionários no exterior e de vendas no exterior como um percentual de respectivos totais.

\section{Resultados da Pesquisa de Campo}

\subsection{Apresentação dos resultados da pesquisa}

A tabulação dos dados da pesquisa revela que $71 \%$ dos respondentes são do sexo masculino e que $29 \%$ pertencem ao sexo feminino. Referente à formação da amostra, $43 \%$ da base são ou foram executivos da Vale ligados à área de internacionalização da empresa; $14 \%$ são executivos do segmento de mineração; outros $14 \%$ provenientes de bancos de investimentos, 7\% são da Previ, 4\% pertencem à academia e $18 \%$ são formados por profissionais da imprensa. Verifica-se que a intenção de obter uma amostra diversificada e representativa foi alcançada pelo estudo. Referente ao cargo ocupado, 39\% dos respondentes são ocupantes de cargo de gerentes/ coordenadores; $25 \%$ são analistas; $18 \%$ são jornalistas; $7 \%$ são diretores, $3 \%$ conselheiros e, por fim, os professores representam $4 \%$ da amostra. Também aqui podem ser observados os efeitos da diversificação da amostra, em razão da apresentação dos diferentes cargos e ocupações entre os respondentes.

A comprovação da qualificação e do grau de excelência dos respondentes está intimamente ligada ao estrato de instrução deles. Dentre os quais, 32\% têm o título de mestrado; $29 \%$ têm o curso superior; $25 \%$ concluíram a pós-graduação e outros $14 \%$ são portadores do título de doutor.

O tempo médio de trabalho no acompanhamento da estratégia de internacionalização da Vale ficou em 5,53 anos, ligeiramente inferior ao 7 anos registrados desde o início do processo de internacionalização da empresa (2001) até hoje. Isto configura senioridade, intensa familiaridade e conhecimento do tema pesquisado. Dividindo por classes, $50 \%$ têm mais de 5 anos de acompanhamento, 32\% têm de 1 a 3 anos de análise e $18 \%$ estão realizando esse acompanhamento de 3 a 5 anos. Abaixo o gráfico 3 apresenta as representações das categorias do tempo médio de acompanhamento da internacionalização da Vale.

No tocante à pergunta número 2 "De acordo com os estudos realizados e conforme artigos e livros publicados, os fatores abaixo são considerados motivadores clássicos para o processo de internacionalização de empresas. Utilizando uma escala de 1 a 5, por favor avalie a importância dos motivadores abaixo". Os principais motivadores para internacionalização apontados pelos respondentes e ordenados de forma decrescente pela média da pontuação obtida estão sumarizados na tabela 2 a seguir:

De acordo com a tabela 2 que apresenta os motivadores priorizados pelos respondentes, o primeiro item "Empresa possui vantagem competitiva relacionada a extração de commodities" e o terceiro item "Assegurar acesso de longo prazo a novas fontes de matérias primas" são motivadores característicos dos países do BRIC. "Busca de novos mercados para fortalecer o negócio existente (margem e volume)" é um motivador característico tanto da escola americana quanto dos países do BRIC. Outro motivador ligado a escola americana é a "Expansão baseada na busca pelo aumento do volume da produção". 
Finalizando a lista priorizada pelos respondentes, "Redução dos custos de operação através da eficiência global em suas operações e escala global" é um motivador característico da escola japonesa. Desta forma, não foi verificado que as referidas empresas adotaram nenhum motivador ligado a escola européia.

\begin{tabular}{|c|c|c|}
\hline Posição & $\begin{array}{c}\text { Motivadores } \\
\text { da Internacionalização }\end{array}$ & $\begin{array}{c}\text { Média da } \\
\text { pontuação obtida }\end{array}$ \\
\hline 1 & $\begin{array}{l}2.15 \text { - Empresa possui vantagem competitiva relacionada a extração } \\
\text { de commodities. }\end{array}$ & 4,61 \\
\hline 2 & $\begin{array}{l}\text { 2.6 - Busca de novos mercados para fortalecer o negócio existente } \\
\text { (margem e volume). }\end{array}$ & 4,50 \\
\hline 3 & $\begin{array}{l}2.16 \text { - Assegurar acesso de longo prazo a novas fontes de matérias } \\
\text { primas. }\end{array}$ & 4.43 \\
\hline 4 & $\begin{array}{l}2.5 \text { - Expansão baseada na busca pelo aumento do volume da } \\
\text { produção. }\end{array}$ & 4,07 \\
\hline 5 & $\begin{array}{l}2.14 \text { - Redução dos custos de operação através da eficiência global } \\
\text { em suas operações e escala global. }\end{array}$ & 3,82 \\
\hline 6 & 2.13 - Desenvolvimento de novas fontes seguras de suprimento. & 3,68 \\
\hline 7 & $\begin{array}{l}2.2 \text { - Oportunidade para levar produtos existentes para mercados } \\
\text { externos. }\end{array}$ & 3,57 \\
\hline 8 & 2.3 - Aumentar a capacidade de aprendizado em uma escala global. & 3,11 \\
\hline 9 & 2.11 - Procura por países de baixo custo para aperfeiçoar a produção. & 3,07 \\
\hline 10 & $\begin{array}{l}2.9 \text { - Baixa pressão local por responsividade e forte pressão para a } \\
\text { redução de custos. }\end{array}$ & 2,82 \\
\hline 11 & 2.12 - Pequeno mercado no país de origem da empresa. & 2,75 \\
\hline 12 & $\begin{array}{l}2.10 \text { - Aproveitar o investimento realizado em pesquisa para } \\
\text { alavancar o processo de inovação. }\end{array}$ & 2,57 \\
\hline 13 & 2.1 - Saturação do mercado local. & 2,50 \\
\hline 14 & $\begin{array}{l}2.4 \text { - Oportunidade para prospecção regional visto a homogeneidade } \\
\text { dos consumidores da região. }\end{array}$ & 2,36 \\
\hline 15 & $\begin{array}{l}2.7 \text { - Forte pressão para a responsividade local e baixa pressão para a } \\
\text { redução de custos. }\end{array}$ & 1,79 \\
\hline 16 & 2.8 - Baixa pressão local por responsividade e pela redução de custos. & 1,64 \\
\hline
\end{tabular}

Tabela 2 - Resultado da Pesquisa - Priorização dos motivadores de internacionalização.

O quadro 5 apresenta na cor cinza-escuro os motivadores que apresentaram interseção entre as conclusões dos autores do trabalho após o processo de leitura do material das empresas, e os cinco motivadores priorizados pelos respondentes da pesquisa. Para esse item, a interseção entre as conclusões dos autores e as indicações principais dos respondentes foi de $80 \%$.

Relativo à pergunta número 3 "Ainda de acordo com estudos realizados, e conforme artigos e livros publicados, estão listadas abaixo as estratégias clássicas empregadas pelas empresas para o processo de internacionalização. Utilizando uma escala de 1 a 5 , por favor, avalie a importância das estratégias abaixo.".

As principais estratégias empregadas pela empresa no processo de internacionalização e priorizadas pelos respondentes estão resumidos na tabela 3 a seguir.

De acordo com a tabela 3 , das estratégias de internacionalização priorizadas pelos respondentes, o primeiro item "Foco na liderança global de sua categorial segmento de mercado." e o terceiro item "Forte investimento na aquisição de empresas de outros países" são característicos dos países do BRIC. "Foco no aumento da receita" e "Distribuição global dos ativos e recursos" são estratégias relacionadas a escola européia. Finalizando a lista priorizada pelos respondentes, "Foco no aumento da lucratividade pela redução de custos" é uma estratégia característica da escola japonesa. Relativo as estratégias de internacionalização 
empregadas pelas empresas de mineração e em particular pela Vale, não foi verificada nenhuma estratégia característica da escola americana.

\begin{tabular}{|c|c|c|}
\hline Posição & $\begin{array}{c}\text { Estratégia } \\
\text { de Internacionalização }\end{array}$ & $\begin{array}{c}\text { Média da } \\
\text { pontuação } \\
\text { obtida }\end{array}$ \\
\hline 1 & 3.19 - Foco na liderança global de sua categoria/ segmento de mercado. & 4,93 \\
\hline 2 & 3.5 - Foco no aumento da receita. & 4,61 \\
\hline 3 & 3.18 - Forte investimento na aquisição de empresas de outros países. & 4,61 \\
\hline 4 & 3.3 - Distribuição global dos ativos e recursos. & 4,25 \\
\hline 5 & 3.15 - Foco no aumento da lucratividade pela redução de custos. & 4,25 \\
\hline 6 & $\begin{array}{l}3.20 \text { - Monetarizando recursos naturais encontrados no país sede e } \\
\text { aproveitando o baixo custo doméstico. }\end{array}$ & 3,68 \\
\hline 7 & 3.7 - Foco na criação e exploração da inovação em uma base mundial. & 3,46 \\
\hline 8 & 3.16 - Replicar o sucesso da estratégia empregada no país sede. & 3,46 \\
\hline 9 & 3.14 - Investimento em um amplo sistema de distribuição. & 3,43 \\
\hline 10 & 3.8 - Produto padrão comercializado da mesma forma em todo o mundo. & 3,21 \\
\hline 11 & 3.6 - Foco no aumento da competição dentro de cada país. & 3,04 \\
\hline 12 & 3.21 - Migração das marcas regionais para marcas globais & 3,00 \\
\hline 13 & $\begin{array}{l}3.9 \text { - Transferência de produtos, processos e estratégias do país de origem } \\
\text { para as unidades externas. }\end{array}$ & 2,96 \\
\hline 14 & $\begin{array}{l}\text { 3.17- Transferência de produtos, processos e estratégias do país de origem } \\
\text { para as unidades externas. }\end{array}$ & 2,86 \\
\hline 15 & $\begin{array}{l}3.2 \text { - Estratégias de prospecção regional visto a homogeneidade dos clientes } \\
\text { da região. }\end{array}$ & 2,64 \\
\hline 16 & $\begin{array}{l}3.13 \text { - Desenvolvimento de produto focado nas similaridades internacionais } \\
\text { em vez das diferenças culturais. }\end{array}$ & 2,64 \\
\hline 17 & 3.4 - Inovação local através da concessão de autonomia para as subsidiárias. & 2,39 \\
\hline 18 & $\begin{array}{l}3.1 \text { - Construção de diferenciação para atender a demanda local dos } \\
\text { consumidores. }\end{array}$ & 2,32 \\
\hline 19 & $\begin{array}{l}3.10 \text { - Centralização das funções de desenvolvimento de produto permitindo } \\
\text { ações de marketing locais. }\end{array}$ & 2,00 \\
\hline 20 & $\begin{array}{l}3.12 \text { - Desenvolvimento de produtos de alto valor agregado e respectiva } \\
\text { padronização através dos países. }\end{array}$ & 1,96 \\
\hline 21 & $\begin{array}{l}3.11 \text { - Diminuição do ciclo de vida dos produtos permitindo constante } \\
\text { lançamento de novos produtos. }\end{array}$ & 1,29 \\
\hline
\end{tabular}

Tabela 3 - Resultado da Pesquisa - Priorização das estratégias de internacionalização.

O quadro 6 traz na cor cinza-escuro as estratégias que apresentaram interseção entre as conclusões do autor do trabalho após o processo de leitura e análise do material das empresas e as cinco principais estratégias indicadas pelos respondentes. Com relação a esse item, a interseção entre as conclusões dos autores e as indicações dos respondentes também foi de $80 \%$.

Finalizando na pergunta número 4 os respondentes foram convidados a responder à pergunta "Para finalizar, estão listadas abaixo os resultados e problemas enfrentados pelas empresas durante o processo de internacionalização. Utilizando uma escala de 1 a 5 , por favor, avalie os resultados abaixo", utilizando-se o mesmo procedimento de tabulação empregado nas perguntas anteriores. Os principais resultados obtidos no processo de internacionalização e que foram priorizados pelos respondentes estão sumarizados na tabela 4:

De acordo com a tabela 4 , dos resultados obtidos pelo processo de internacionalização e priorizados pelos respondentes, o primeiro item "Criação de equipes gerenciais capazes de enfrentar os desafios ligados a globalização", o segundo item "Desenvolvimento do conhecimento em operações de fusões e aquisições", o terceiro item "Maior influência das suas empresas no comércio internacional." e o quarto item "Amplo esforço de ampliação do portfólio de produtos e países" são resultados característicos dos países do BRIC. Somente o 
quinto item "Focaliza na economia de escala" é um resultado característico da escola japonesa. Desta forma, segundo os respondentes não foram priorizados resultados das escolas americana e européia no processo de internacionalização das três empresas de mineração e em particular da Vale.

\begin{tabular}{|c|c|c|}
\hline Posição & $\begin{array}{c}\text { Resultados } \\
\text { da Internacionalização }\end{array}$ & $\begin{array}{c}\text { Média da } \\
\text { pontuação obtida }\end{array}$ \\
\hline 1 & $\begin{array}{l}4.13 \text { - Criação de equipes gerenciais capazes de enfrentar os desafios } \\
\text { ligados a globalização. }\end{array}$ & 4,36 \\
\hline 2 & $\begin{array}{l}4.14 \text { - Desenvolvimento do conhecimento em operações de fusões e } \\
\text { aquisições }\end{array}$ & 4,29 \\
\hline 3 & 4.12 - Maior influência das suas empresas no comércio internacional. & 4,29 \\
\hline 4 & 4.11 - Amplo esforço de ampliação do portfólio de produtos e países. & 4,29 \\
\hline 5 & 4.10 - Focaliza na economia de escala. & 3,61 \\
\hline 6 & $\begin{array}{l}4.1 \text { - Problemas de ineficiência e inabilidade para explorar o conhecimento } \\
\text { e competência gerados por outras unidades }\end{array}$ & 2,93 \\
\hline 7 & $\begin{array}{l}4.7 \text { - Comprometimento da flexibilidade e do processo de aprendizado não } \\
\text { capturando o conhecimento gerado nas demais unidades. }\end{array}$ & 2,82 \\
\hline 8 & 4.2 - Fraca integração global & 2,82 \\
\hline 9 & $\begin{array}{l}4.3 \text { - Não alcança a economia de escala implicando em custos de produção } \\
\text { mais altos. }\end{array}$ & 2,18 \\
\hline 10 & $\begin{array}{l}4.9 \text { Reconhecimento da vulnerabilidade da competição baseada somente } \\
\text { nas vantagens de custo de mão-de-obra e escala. }\end{array}$ & 2,11 \\
\hline 11 & 4.4 - Falta de um forte sistema de distribuição. & 2,00 \\
\hline 12 & 4.6 - Deficiência em atingir a escala global. & 1,71 \\
\hline 13 & $\begin{array}{l}4.5 \text { - Por não ter adaptação local, produtos não satisfazem as necessidades } \\
\text { em todos os países, levando a uma perda de participação de mercado. }\end{array}$ & 1,54 \\
\hline 14 & 4.8 - Sem resposta as demandas local (falta de responsividade). & 1,50 \\
\hline
\end{tabular}

Tabela 4 - Resultado da Pesquisa - Priorização dos resultados obtidos na internacionalização.

O quadro 7 apresenta na cor cinza-escuro os resultados que apresentaram interseção entre as conclusões dos autores do trabalho após o processo de análise do material das empresas e os cinco principais resultados indicados pelos respondentes. Para esse item, a interseção entre as conclusões dos autores e indicações dos respondentes foi de $100 \%$.

\section{Análises dos Resultados e Recomendações Estratégicas}

O objetivo principal desta seção é apresentar as comparações entre os modelos de internacionalização das três principais empresas mundiais de mineração, seus motivadores, estratégias e resultados e as respostas dos entrevistados no processo de pesquisa.

\subsection{Modelo de internacionalização do segmento de mineração.}

O mercado de mineração é caracterizado pelo consumo da produção exercido pelas nações desenvolvidas e alguns poucos países emergentes com destaque para China e Índia. Já a produção - sob a responsabilidade dos países emergentes - é também caracterizada pelo desequilíbrio que por vezes causa preocupação entre as nações consumidoras, que zelam pela manutenção da fonte segura de fornecimento, e, ainda, geram apreensão entre os países exportadores que buscam formas e fontes de acessos a novos mercados.

Utilizando novamente os conceitos de Bartlett (1992), Beamish (2003), Ghoshal (1993), Hill (2005) e Hitt et al (2001) além dos estudos da Booz Allen (2007), BCG (2008) e UNCTAD (2007) e baseado na opinião dos respondentes da pesquisa foi possível, para os autores da pesquisa, a criação dos quadros abaixo 5 a 7 , para reforçar a compreensão das Menezes, J. D. C.; Campos Filho, L. A. N. 
características predominantes de cada escola, e as práticas efetivamente utilizadas pelo segmento de mineração e em particular pela Vale. Conforme descrito anteriormente, a cor cinza-escuro demonstra a interseção entre as conclusões dos autores e a percepção dos respondentes. A cor cinza-clara apresenta outros itens apontados pelos autores do estudo. $\mathrm{O}$ quadro 5 apresenta a priorização dos motivadores para internacionalização das empresas européias, americanas, japonesas e países do BRIC e a opinião dos respondentes.

\begin{tabular}{|c|c|c|c|c|}
\hline & Empresas européias & $\begin{array}{c}\text { Empresas } \\
\text { americanas }\end{array}$ & $\begin{array}{l}\text { Empresas } \\
\text { japonesas }\end{array}$ & $\begin{array}{c}\text { Empresas dos } \\
\text { BRICs }\end{array}$ \\
\hline \multirow{5}{*}{$\begin{array}{l}\text { Motiva- } \\
\text { dores } \\
\text { estraté- } \\
\text { gicos }\end{array}$} & & $\begin{array}{l}\text { Expansão baseada } \\
\text { na busca pelo } \\
\text { aumento do volume } \\
\text { da produção. }\end{array}$ & $\begin{array}{l}\text { Pequeno mercado } \\
\text { no país de origem } \\
\text { da empresa. }\end{array}$ & $\begin{array}{l}\text { Vantagem competitiva } \\
\text { relacionada à extração } \\
\text { de commodities. }\end{array}$ \\
\hline & $\begin{array}{c}\text { Levar produtos } \\
\text { existentes para } \\
\text { mercados externos. }\end{array}$ & $\begin{array}{c}\text { Novos mercados } \\
\text { para fortalecer } \\
\text { negócio (margem e } \\
\text { volume) }\end{array}$ & $\begin{array}{l}\text { Desenvolvimento } \\
\text { de novas fontes } \\
\text { seguras de } \\
\text { suprimento. }\end{array}$ & $\begin{array}{l}\text { Novos mercados para } \\
\text { fortalecer o negócio } \\
\text { (margem e volume). }\end{array}$ \\
\hline & $\begin{array}{l}\text { Forte pressão para a } \\
\text { responsividade local e } \\
\text { baixa pressão para } \\
\text { redução de custos. }\end{array}$ & $\begin{array}{l}\text { Baixa pressão local } \\
\text { para a } \\
\text { responsividade e } \\
\text { redução de custos. }\end{array}$ & $\begin{array}{l}\text { Baixa pressão local } \\
\text { para a } \\
\text { responsividade e } \\
\text { forte pressão para a } \\
\text { redução de custos. }\end{array}$ & $\begin{array}{l}\text { Assegurar acesso de } \\
\text { longo prazo a fontes } \\
\text { de matérias-primas. }\end{array}$ \\
\hline & $\begin{array}{l}\text { Aumentar a capacidade } \\
\text { de aprendizado em } \\
\text { escala global. }\end{array}$ & $\begin{array}{l}\text { Maximizar o } \\
\text { investimento } \\
\text { realizado em } \\
\text { pesquisa para } \\
\text { alavancar a } \\
\text { inovação. }\end{array}$ & $\begin{array}{l}\text { Redução dos custos } \\
\text { de operação por } \\
\text { meio da eficiência e } \\
\text { escala global. }\end{array}$ & $\begin{array}{c}\text { Maximizar } \\
\text { investimento feito em } \\
\text { pesquisa e } \\
\text { desenvolvimento. }\end{array}$ \\
\hline & $\begin{array}{l}\text { Prospecção regional, } \\
\text { haja vista a } \\
\text { homogeneidade dos } \\
\text { consumidores da } \\
\text { região. }\end{array}$ & $\begin{array}{l}\text { Procura por países } \\
\text { de baixo custo para } \\
\text { otimizar produção. }\end{array}$ & & \\
\hline
\end{tabular}

Quadro 5 - Priorização dos motivadores para internacionalização das empresas européias, americanas, japonesas e países do BRIC.

Legenda: $\square$ Listados pelos Autores $\square$ Listados pelos autores e priorizados pelos respondentes

. Priorizado pelos respondentes e não listado pelos autores

De acordo com o quadro 5, percebe-se que o segmento de mineração - em função da característica e dinâmica do mercado - teve como principais motivadores para a internacionalização, fatores mais próximos da escola japonesa, americana e países do BRIC. Por essa proximidade, então, afastou-se da escola européia, por objetivar principalmente a "busca de novos mercados para fortalecer o negócio existente", "assegurar aceso de longo prazo a novas fontes",na "vantagem competitiva relacionada a extração de commodities" e a "expansão baseada na busca pelo aumento do volume de produção".

O quadro 6 apresenta a priorização das estratégias empregadas para a internacionalização das empresas européias, americanas, japonesas e países do BRIC e a opinião dos respondentes.

De acordo com o quadro 6, assim como na análise dos motivadores estratégicos, percebe-se que relativo as estratégias adotadas, o mercado de mineração apresenta maior relação com as escolas européias e países do BRIC, baixa relação com a escola japonesa e nenhuma relação com as estratégias da escola americana, visto que das estratégias de internacionalização priorizadas pelos respondentes, o primeiro item "Foco na liderança global de sua categorial segmento de mercado." e o terceiro item "Forte investimento na aquisição de empresas de outros países" são característicos dos países do BRIC. "Foco no Transnacionais Brasileiras: Motivadores e Resultados do Processo de Internacionalização da Vale 
aumento da receita" e "Distribuição global dos ativos e recursos" são estratégias relacionadas a escola européia.

\begin{tabular}{|c|c|c|c|c|}
\hline & $\begin{array}{l}\text { Empresas } \\
\text { européias }\end{array}$ & $\begin{array}{c}\text { Empresas } \\
\text { americanas }\end{array}$ & $\begin{array}{l}\text { Empresas } \\
\text { japonesas }\end{array}$ & $\begin{array}{c}\text { Empresas dos } \\
\text { BRICs }\end{array}$ \\
\hline \multirow{7}{*}{$\begin{array}{l}\text { Estratégias } \\
\text { adotadas }\end{array}$} & $\begin{array}{c}\text { Construção de } \\
\text { diferenciação para } \\
\text { atender à demanda } \\
\text { local dos } \\
\text { consumidores. }\end{array}$ & $\begin{array}{l}\text { Foco na criação e } \\
\text { exploração da } \\
\text { inovação em uma } \\
\text { base mundial. }\end{array}$ & $\begin{array}{l}\text { Diminuição do } \\
\text { ciclo de vida dos } \\
\text { produtos, } \\
\text { permitindo } \\
\text { constante } \\
\text { lançamento de } \\
\text { produtos. }\end{array}$ & $\begin{array}{l}\text { Replicar o sucesso da } \\
\text { estratégia empregada } \\
\text { no país-sede. }\end{array}$ \\
\hline & $\begin{array}{c}\text { Estratégias de } \\
\text { prospecção regional } \\
\text { visto a } \\
\text { homogeneidade dos } \\
\text { clientes da região. }\end{array}$ & $\begin{array}{l}\text { Produto padrão } \\
\text { comercializado da } \\
\text { mesma forma em } \\
\text { todo o mundo. }\end{array}$ & $\begin{array}{c}\text { Desenvolvimento } \\
\text { de produtos de alto } \\
\text { valor agregado e } \\
\text { padronização } \\
\text { através dos países. }\end{array}$ & $\begin{array}{c}\text { Transferência de } \\
\text { produtos, processos e } \\
\text { estratégias do país de } \\
\text { origem para as } \\
\text { unidades externas. }\end{array}$ \\
\hline & $\begin{array}{l}\text { Distribuição global } \\
\text { de ativos e recursos. }\end{array}$ & $\begin{array}{l}\text { Transferência de } \\
\text { produtos e } \\
\text { estratégias do país } \\
\text { de origem para as } \\
\text { unidades externas. }\end{array}$ & $\begin{array}{c}\text { Desenvolvimento } \\
\text { de produto focado } \\
\text { nas similaridades } \\
\text { internacionais em } \\
\text { vez das diferenças } \\
\text { culturais. }\end{array}$ & $\begin{array}{c}\text { Estratégias de } \\
\text { prospecção regional } \\
\text { em virtude da } \\
\text { homogeneidade da } \\
\text { região - empresas do } \\
\text { MERCOSUL. }\end{array}$ \\
\hline & $\begin{array}{l}\text { Inovação local por } \\
\text { intermédio da } \\
\text { concessão de } \\
\text { autonomia para as } \\
\text { subsidiárias. } \\
\end{array}$ & $\begin{array}{l}\text { Centralização do } \\
\text { desenvolvimento de } \\
\text { produto permitindo } \\
\text { ação local de } \\
\text { marketing }\end{array}$ & $\begin{array}{l}\text { Investimento em } \\
\text { amplo sistema de } \\
\text { distribuição. }\end{array}$ & $\begin{array}{l}\text { Investimento forte na } \\
\text { aquisição de empresas } \\
\text { de outros países. }\end{array}$ \\
\hline & $\begin{array}{c}\text { Foco no aumento da } \\
\text { receita. }\end{array}$ & & $\begin{array}{l}\text { Foco no aumento } \\
\text { da lucratividade } \\
\text { pela redução de } \\
\text { custos. }\end{array}$ & $\begin{array}{c}\text { Assumir a liderança } \\
\text { global da categoria de } \\
\text { mercado. }\end{array}$ \\
\hline & $\begin{array}{l}\text { Foco no aumento da } \\
\text { competição dentro de } \\
\text { cada país. }\end{array}$ & & & $\begin{array}{l}\text { Monetarização dos } \\
\text { recursos naturais do } \\
\text { país-sede e o } \\
\text { aproveitamento do } \\
\text { baixo custo } \\
\text { doméstico. }\end{array}$ \\
\hline & $\begin{array}{c}\text { Atua no modelo de } \\
\text { empresa } \\
\text { multinacional. }\end{array}$ & $\begin{array}{c}\text { Atua no modelo de } \\
\text { empresa } \\
\text { internacional. }\end{array}$ & $\begin{array}{l}\text { Atua no modelo de } \\
\text { empresa global. }\end{array}$ & $\begin{array}{l}\text { Tornar as marcas } \\
\text { globais. }\end{array}$ \\
\hline
\end{tabular}

Quadro 6 - Priorização das estratégias adotadas pelas empresas européias, americanas, japonesas e países do BRIC no processo de internacionalização.

Legenda: $\square \quad$ Listados pelo Autores $\quad \square \quad$ Listados pelos autores e priorizados pelos respondentes Priorizado pelos respondentes e não listado pelos autores

O quadro 7 apresenta a priorização dos resultados alcançados pela internacionalização das empresas européias, americanas, japonesas e países do BRIC e a opinião dos respondentes.

No quadro 7, destaca-se a predominância da escola dos BRICs nos resultados obtidos visto o primeiro item priorizado "Criação de equipes gerenciais capazes de enfrentar os desafios ligados a globalização", o segundo item "Desenvolvimento do conhecimento em operações de fusões e aquisições", o terceiro item "Maior influência das suas empresas no comércio internacional." e o quarto item "Amplo esforço de ampliação do portfólio de produtos e países" são resultados característicos dos países do BRIC. Somente o quinto item "Focaliza na economia de escala" é um resultado característico da escola japonesa. Desta 
forma, segundo os respondentes não foram priorizados resultados das escolas americana e européia no processo de internacionalização das três empresas de mineração e em particular da Vale.

\begin{tabular}{|c|c|c|c|c|}
\hline & $\begin{array}{l}\text { Empresas } \\
\text { européias }\end{array}$ & $\begin{array}{c}\text { Empresas } \\
\text { americanas }\end{array}$ & $\begin{array}{l}\text { Empresas } \\
\text { japonesas }\end{array}$ & $\begin{array}{c}\text { Empresas dos } \\
\text { BRICs }\end{array}$ \\
\hline \multirow{4}{*}{$\begin{array}{l}\text { Resultados } \\
\text { alcançados }\end{array}$} & $\begin{array}{c}\text { Ineficiência e } \\
\text { inabilidade para } \\
\text { explorar o } \\
\text { conhecimento e } \\
\text { alcançar a } \\
\text { competência, gerados } \\
\text { por unidades } \\
\text { internacionais. }\end{array}$ & $\begin{array}{l}\text { Falta de sistema } \\
\text { vigoroso de } \\
\text { distribuição. }\end{array}$ & $\begin{array}{l}\text { Comprometimento } \\
\text { da flexibilidade e } \\
\text { do aprendizado, por } \\
\text { não ser capaz de } \\
\text { reter o } \\
\text { conhecimento } \\
\text { gerado nas demais } \\
\text { unidades. }\end{array}$ & $\begin{array}{l}\text { Grande esforço de } \\
\text { ampliaçãa do portfólio } \\
\text { de produtos e países. }\end{array}$ \\
\hline & $\begin{array}{l}\text { Fraca integração } \\
\text { global. }\end{array}$ & $\begin{array}{c}\text { Por não ter } \\
\text { adaptação local, } \\
\text { produtos não } \\
\text { satisfazem as } \\
\text { necessidades em } \\
\text { todos os países. }\end{array}$ & $\begin{array}{l}\text { Sem resposta às } \\
\text { demandas locais. }\end{array}$ & $\begin{array}{l}\text { Maior influência das } \\
\text { empresas no comércio } \\
\text { internacional. }\end{array}$ \\
\hline & $\begin{array}{c}\text { Sem economia de } \\
\text { escala implicando em } \\
\text { custos mais } \\
\text { altos. }\end{array}$ & $\begin{array}{l}\text { Deficiência em } \\
\text { atingir a escala } \\
\text { global. }\end{array}$ & $\begin{array}{l}\text { Vulnerabilidade da } \\
\text { competição baseada } \\
\text { no custo de mão- } \\
\text { de- obra e escala. }\end{array}$ & $\begin{array}{l}\text { Criar equipes capazes } \\
\text { de enfrentar desafios } \\
\text { ligados à globalização }\end{array}$ \\
\hline & & & $\begin{array}{c}\text { Focaliza na } \\
\text { economia de escala }\end{array}$ & $\begin{array}{c}\text { Desenvolver } \\
\text { conhecimento em } \\
\text { fusão e aquisição. }\end{array}$ \\
\hline $\begin{array}{c}\text { Exemplos } \\
\text { de } \\
\text { empresas }\end{array}$ & $\begin{array}{l}\text { Unilever, Philips e } \\
\text { Nestlé }\end{array}$ & Kraft, Pfizer e GE & $\begin{array}{l}\text { Toyota, Canon, } \\
\text { Komatsu e } \\
\text { Matsushita }\end{array}$ & $\begin{array}{c}\text { Vale e Embraer, } \\
\text { Lenovo, India - Wipro } \\
\text { e Gazprom }\end{array}$ \\
\hline
\end{tabular}

Quadro 7 - Priorização dos resultados obtidos pelas empresas européias, americanas, japonesas e países do BRIC no processo de internacionalização.

Legenda: $\square \quad$ Listados pelos Autores $\quad \square \quad$ Listados pelos autores e priorizados pelos respondentes

Desta forma, quando se analisa os resultados conjuntos dos motivadores, estratégias e resultados (quadros 5 a 7) verifica-se que parece começar a existir um outro modelo de internacionalização de empresas, modelo este que conjuga as melhores e mais pertinentes práticas (a cada segmento de atuação) existentes nas escolas americanas, européias, japonesas e países do BRIC. Cabe ressaltar que esta análise é restrita ao segmento de mineração e não pode ser aplicada de forma imediata a nenhum outro segmento sem conhecimento e análise de sua dinâmica e processos.

\section{Considerações Finais}

Dentro da contribuição para o estudo de estratégias internacionais, Porter (1988) afirmou que a competição internacional tornou-se uma das prioridades estratégicas das grandes corporações.

O presente estudo analisou o processo de internacionalização das três principais empresas mundiais de mineração, analisando os diferentes modelos de internacionalização e sua relação com alguma escola específica e de forma detalhada a Vale, empresa brasileira e segunda colocada no ranking das maiores empresas do segmento de mineração. Para tanto, foi realizada pesquisa sobre a literatura nacional e internacional sobre o tema. Esse esforço foi complementado por um trabalho de pesquisa de campo com uma base de resposta de 28 respondentes de diferentes segmentos de mercado. As evidências e fatos coletados aqui Transnacionais Brasileiras: Motivadores e Resultados do Processo de Internacionalização da Vale 
descritos comprovam que a Vale traçou e implantou a estratégia pró-ativa de internacionalização, ao conquistar rapidamente o espaço, por estabelecer as atividades em diferentes países. Isso viabilizou o crescimento da companhia no setor de mineração mundial. O fator preponderante para esse sucesso foi, entre outros, a clara percepção de mercado e o entendimento por parte da direção da empresa dos principais motivadores para essa empreitada.

O resultado obtido pelo estudo indicou os principais motivadores estratégicos da empresa para esse processo, a trajetória de evolução no exterior, os principais indicadores do processo medidos conforme as métricas de avaliação da UNCTAD, e permitiu ainda a formulação de recomendações estratégicas que fortaleçam o lugar de destaque da empresa na indústria mundial de mineração, não englobando o estudo de outros setores de mercado. Também é importante destacar que os resultados apresentados indicam que a Vale e as demais empresas de mineração analisadas, por terem feito um movimento tardio de internacionalização, ao contrário do setor automotivo, por exemplo, no qual o país-sede da empresa tem profunda influência no modelo de internacionalização, as empresas de mineração adotaram uma combinação híbrida de motivadores e estratégias empregadas pelas escolas americana, japonesa, européia e países do BRIC. Para isso, utilizaram-se das melhores e mais adequadas práticas empresariais existentes ao modelo de negócio e processos, independentemente da influência do país-sede.

As limitações atreladas a presente pesquisa estão relacionadas ao tamanho da amostra (28 respondentes) e ao fato de que $85 \%$ das entrevistas foi realizada pela Internet. Isso aconteceu em razão da agenda sempre restrita dos respondentes, bem como a dificuldade de deslocamentos a outras regiões do país, e pela falta de pesquisas brasileiras para comparação direta com os resultados obtidos.

\section{Referências}

APPOLINÁRIO, Fábio. Metodologia da Ciência - Filosofia e Prática da Pesquisa. 1. ed. São Paulo: Pioneira Thompson Learning, 2006.

BALARIN, Raquel e DURÃO, Vera. Vale pode pagar parte da compra da Xstrata com ações preferenciais. Valor Econômico, São Paulo, p.b1, 21 jan. 2008.

BARTLETT, Christopher et al. Transnational Management. Mc Graw Hill, 1992.

BASSI, Eduardo. Globalização de Negócios. Cultura Editores Associados, 1999.

BEAMISH, Paul et al. International Management. MC Granel Times Custo Publishing, 2003.

BERMAN, Dennis. Como uma fusão BHP-Rio Tinto teria impacto sobre todo o mundo. Valor Econômico, São Paulo, 12 fev. 2008. Caderno Empresas, p. b10.

BLOOMBERG. Ranking de Valorização das Empresas. Acesso restrito à empresas. Acesso em 17 de Janeiro de 2008.

BOOZ Allen. Setting out to conquer the world. Disponível em: <www.boozallen.com>. Acesso em: 10 dez. 2007.

BOSTON Consulting Group. The 2008 BCG 100 New global challengers. USA. dez. 2007. 
COOPER, Donald R. E SCHINDLER, Pamela S. Métodos de Pesquisa em Administração. 7. ed. Porto Alegre: Bookman, 2003.

COSTA, Melina. Desta vez o risco é maior. Revista Exame, São Paulo: Editora Abril, 12 mar. 2008.

COTIAS, Adriana e CAMBA, Daniela. O valor da Vale. Valor Econômico, São Paulo, p. d1, 10 mar. 2008.

DURÃO, Vera.Vale e Xstrata em busca de novos ativos. Valor Econômico, São Paulo, p. b9, 27 mar. 2008.

DURÃO, Vera e RIBEIRO, Ivo. Vale desiste de comprar a Xstrata. Valor Econômico, São Paulo, 26 mar. 2008.

GARRIDO, Ivan et al. Orientação para o mercado externo, estratégias de entrada em mercados internacionais e performance internacional: proposições para um modelo conceitual. BASE - Unisinos. Janeiro-Abril 2006.

GHOSHAL, Sumantra. NOHRIA, Mitin. Cavalos em Pistas de Corrida: Formas Organizacionais de Companhias Multinacionais. Sloan Management Review, 1993.

GOLDMAN, Sachs. Brics and Beyond, nov. 2007.

HILL, Charles. International Business. McGraw-Hill Higher Education, 2005.

HITT, Michael et al. Strategic Management: Competitiveness and Globalization. South Western College Publishing, 2001.

MACQUARIE RESEARCH. Iron One Industry Outlook. May 2006.

MATTAR, FAUZE NAJIB. Pesquisa de Marketing. São Paulo: Atlas, 1999.

MEYER, Carolina. A Inco virou problema. Revista Exame, São Paulo: Editora Abril, 21 mai. 2008.

O MINÉRIO boom. Revista Exame, São Paulo: Editora Abril, ano 40, n. 24, ed. 882, 6 dez. 2006.

OHMAE, Kenichi. The Global logic of strategic alliances. Harvard Business Review, mar./apr. 1989.

PORTER, Michael. Técnicas para análise de indústrias e da concorrência. São Paulo: Campus, 2001.

PORTER, Michael e Montgomery, Cynthia, A. Estratégia - a busca da vantagem competitiva. Editora Campus. 1998. 
REGALADO, Antonio. Quem são esses Brasileiros? Como a Vale muda a mineração mundial. Valor Econômico, São Paulo, p. b11, 25 abr. 2008.

UNITED NATIONS CONFERENCE ON TRADE AND DEVELOPMENT - UNCTAD World Invest Report 2007. Consulta realizada em http://www.unctad.org/en/doc em 14 de fevereiro de 2008.

VALE à pena Internacionalizar? FUNDAÇÃO Dom Cabral - FDC. Revista Dom, São Paulo: dez. 2006.

VALE planeja aquisições após provável compra da Inco. Gazeta Mercantil, Rio de Janeiro, 17 out. 2006.

VALVERDE, Rosembergue. Vantagens comparativas do BRIC e Gestão do Comércio Exterior. XXX Encontro da ANPAD. Salvador, set. 2006.

VERNON, Raymond. The product cycle hypothesis in a new international environment. Oxford Bulletin of Economics \& Statistics, nov. 79, v. 41, Issue 4, p.255-267.

WHITELOCK, J. Theories of internalization and their impact on market entry. International Marketing Review. ed. 19, n. 4, 2002.

YIP, George. Estratégia Global ... Em um mundo de Nações? Sloan Management Review. p.29, 1989.

ZORZAL E SILVA, Marta. Estratégia empresarial e desenvolvimento econômico: o caso da Companhia Vale do Rio Doce (CVRD). XXV Encontro da ANPAD. São Paulo, set. 2001. 